\title{
Masa escrotal como presentación de divertículo uretral gigante
}

\author{
Gómez Pascual JA, Morales Jiménez P, Hernández Alcaraz D, Machuca Santacruz J, \\ Vozmediano Chicharro R, Baena González V.
}

Servicio de Urología. Hospital Regional Universitario Carlos Haya. Málaga.

Actas Urol Esp. 2008;32(8):847-849

\section{RESUMEN}

MASA ESCROTAL COMO PRESENTACIÓN DE DIVERTÍCULO URETRAL GIGANTE

El divertículo uretral en el varón es una entidad rara que puede ser congénita o adquirida. Son comunes en pacientes parapléjicos que son propensos a desarrollar este problema de forma adquirida debido a cateterizaciones prolongadas. Las enfermedades mas frecuentes en pacientes lesionados medulares son estenosis, fístulas y divertículos. Pacientes con divertículos típicamente se presentan con síntomas de incontinencia urinaria, disuria, dolor perineal o una masa genital o en periné. El tratamiento de elección es siempre quirúrgico y debería realizarse una extirpación completa del mismo.

Palabras clave: Divertículo uretral. Varón. Masa escrotal.

\section{ABSTRACT \\ SCROTAL MASS PRESENTING AS GIANT URETHRAL DIVERTICULUM}

Urethral diverticulum in the male is a rare entity that may be congenital or acquired. They are common in paraplegic patients, who are prone to developing this disorder on an acquired basis because of prolonged catheterization. The most common diseases in patients with spinal cord injury are stricture, fistula and diverticula. Patients with diverticula typically present with symptoms of urinary incontinence, dysuria, perineal pain, or a mass on the ventral aspect of the genitalia or perineum. Treatment of choice is always surgical and a complete extirpation should be performed.

Keywords: Urethral diverticulum. Male. Scrotal mass.

$\mathrm{E}^{\prime}$ divertículo uretral es una patología infrecuente en el varón y casi siempre se localiza a nivel de uretra peneana. La mayoría de los casos de divertículo masculino son adquiridos ${ }^{1}$ y ocurren en pacientes lesionados medulares como consecuencia de traumatismos uretrales repetidos por cateterismo vesical, lo que puede conllevar a necrosis isquémica o séptica, provocando un absceso que puede destruir la mucosa uretral y el tejido esponjoso, reemplazándolo finalmente por tejido cicatricial y pseudodivertículos ${ }^{2}$. Cursan clínicamente de manera variada y existen también formas congénitas aunque no son frecuentes. Su tratamiento habitualmente es quirúrgico.

\section{CASO CLÍNICO}

Presentamos el caso de un varón de 68 años con vejiga neurógena secundaria a mielomeningocele congénito con hipoactividad vesical e incontinencia. Entre sus antecedentes figuran varias sesiones de litotricia sobre litiasis vesicales y ureterales, una cistolitotomía hace 25 años y dos litofragmentaciones mecánicas por litiasis de uretra posterior. Actualmente es portador de colector urinario.

Tras revisión en consulta el paciente refiere infecciones urinarias recurrentes y micción ayudada por expresión manual escrotal de meses de evolución. La exploración física reveló una masa escrotal de gran tamaño con salida de orina por meato 
uretral cuando se presionaba. Ante la sospecha de lesión uretral versus herniación vesical se realiza uretrografía retrógrada (Fig. 1) evidenciando un divertículo de gran tamaño que se rellena de contraste en su totalidad. La uretrocistoscopia flexible confirmó el diagnóstico de divertículo uretral de gran tamaño hacia escroto y trayecto uretral con aspecto esclerótico.

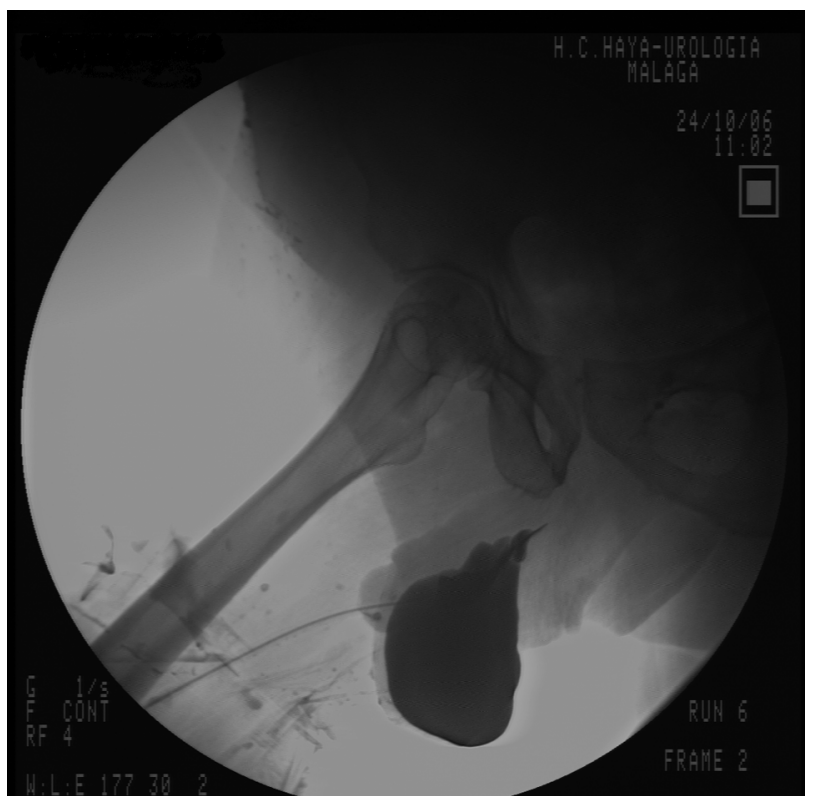

FIGURA 1. Uretrografía retrógrada donde se aprecia gran diverticulo uretral localizado a nivel escrotal que se rellena de contraste en su totalidad.

Se realizó tratamiento quirúrgico consistente en diverticulectomía y cierre uretral simple con interposición de dartos. Para ello se inició la intervención disecando el divertículo y todo su cuello avanzando hasta la zona mas estrecha en su unión con la uretra, exponiéndolo en su totalidad (Fig. 2). Se extirpó todo el cuello y la zona uretral de implantación quedando un defecto uretral de aproximadamente $1 \mathrm{~cm}$ (Fig. 3) que se cerró con puntos sueltos de 4/0 Polydioxano. Se interpuso dartos peneano como medida de seguridad para evitar fístulas. A los 24 días se hizo uretrografía retrógrada visualizando uretra íntegra en su totalidad (Fig. 4).

\section{DISCUSIÓN}

El divertículo uretral en el varón es una patología rara. Sus formas mas frecuentes son las adquiridas (80-90\%). Éstas ocurren en pacientes lesionados medulares en los que el cateterismo vesical de

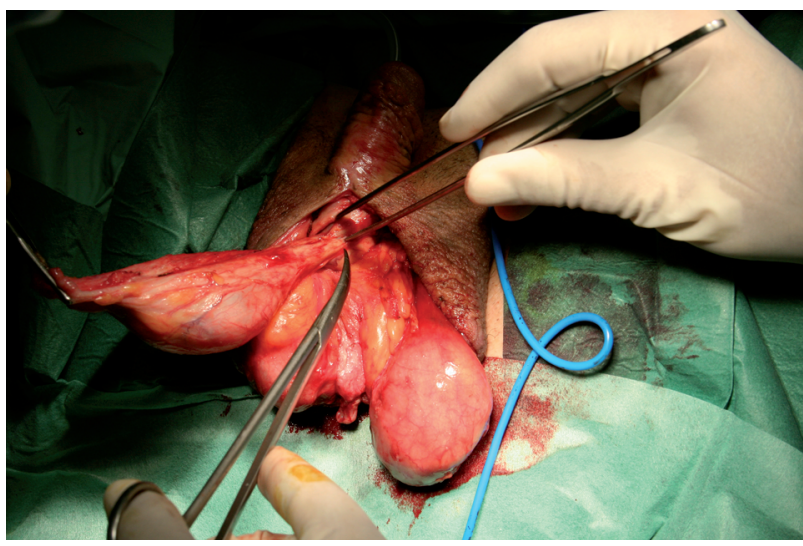

FIGURA 2. Detalle de la intervención: Exposición completa del divertículo tras su completa disección.

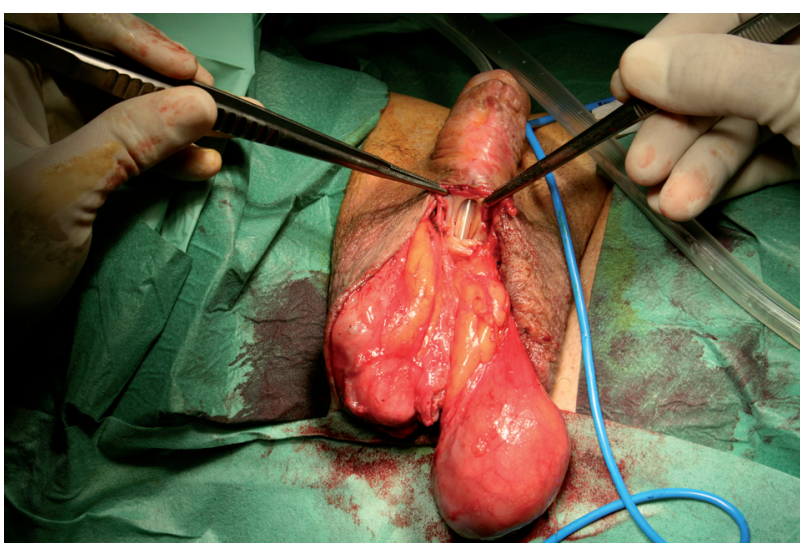

FIGURA 3. Visualización del defecto uretral una vez extir pado el diverticulo hasta su cuello. Resección con már genes quedando un defecto de $1 \mathrm{~cm}$ aproximadamente.

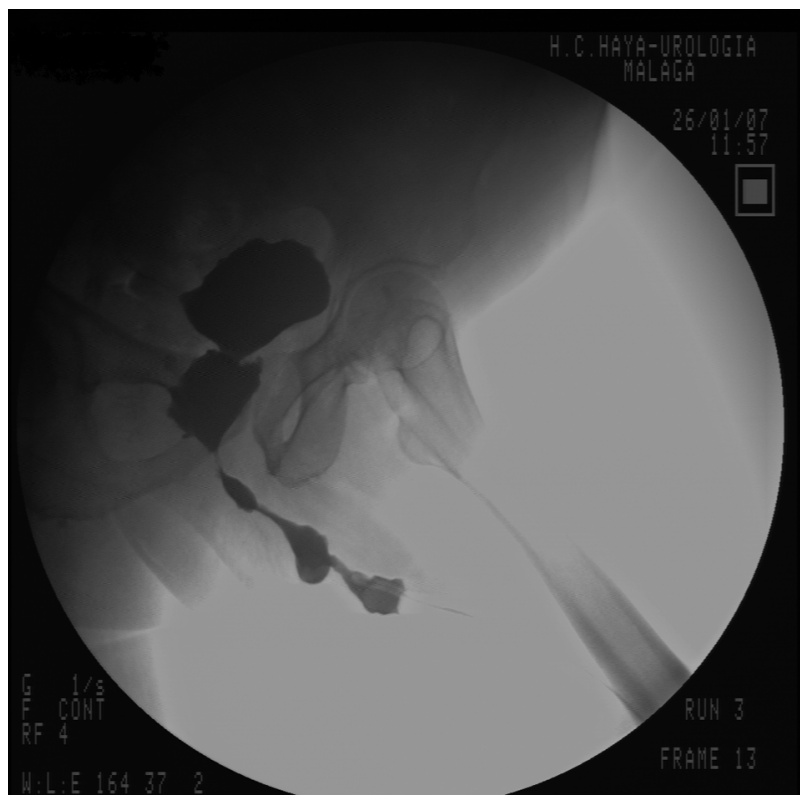

FIGURA 4. Uretrografia retrógrada transcurrido un mes desde la intervención. 
forma permanente o intermitente provoca un traumatismo repetido en la uretra. Puede aparecer asî mismo como complicación del Esfínter Urinario Artificial $^{4}$ y tras cirugía uretral ${ }^{5}$. La mucosa uretral puede sufrir isquemia e infección produciendo cicatrices y finalmente pseudodivertículos. La zona de la uretra más frecuentemente implicada es la uretra peneana, concretamente el ángulo penoescrotal. Las formas congénitas ocupan un $20 \%$ de los casos y son muy raras.

La forma de presentación clínica mas frecuente es la infección urinaria de repetición, aunque también son frecuentes la hematuria, dificultad miccional e incluso retención aguda de orina. La incontinencia urinaria y el dolor perineal asociado o no a masa genital y perineal son síntomas menos comunes.

Aunque la prueba diagnóstica de elección es la uretrografía retrógrada, conviene resaltar el papel de la Resonancia Nuclear Magnética (RNM) ${ }^{3}$. Mientras la primera constituye el "gold standard" en el diagnóstico por imagen de esta patología, la RNM es también útil dado que puede mostrar la extensión del divertículo, la afectación o no del tejido esponjoso subyacente y estos hallazgos determinarían la mejor modalidad terapéutica (endoscópica o exéresis abierta). También se ha descrito la utilización del cistoscopio flexible ${ }^{4}$ como prueba diagnóstica, ya que puede ayudar a descartar cuerpos extraños, cálculos o tumor dentro del divertículo ${ }^{5}$.

La escintigrafía ${ }^{1}$ también se ha utilizado como prueba diagnóstica, pero hay que tener en cuenta que sin un conocimiento de la Historia Clínica del paciente, las imágenes de colección del trazador en el escroto pueden ser confundidas con otras entidades clínicas como extravasación debida a lesión uretral o herniación vesical ${ }^{1}$.

El tratamiento de elección es la exéresis del divertículo y la uretroplastia. En algunas ocasiones se han realizado tratamientos endocópicos en divertículos de pequeño tamaño siempre y cuando haya integridad del cuerpo esponjoso y el tejido de soporte esté intacto ${ }^{3}$. La cirugía abierta en forma de diverticulectomía sigue siendo de elección. Si el defecto uretral es muy grande pueden utilizarse injertos libres extragenitales colocados de forma ventral ${ }^{5}$ que pueden evitar la formación de fístulas y recidivas derivadas de cierres simples.

\section{CONCLUSIONES}

La existencia de infecciones urinarias recurrentes en pacientes con lesión espinal que precisen cateterización vesical de forma continua o intermitente debe conllevar a su exploración física para descartar masas escrotales o perineales. La sospecha de divertículo vesical hace necesaria la realización de uretrografía retrógrada. La cistoscopia flexible es útil para confirmar el diagnóstico y descartar patología asociada al divertículo. El tratamiento de elección es quirúrgico en la mayoría de los casos en forma de diverticulectomía abierta y uretroplastia con cierre simple o con injertos libres extragenitales aunque en algunas ocasiones se pueden hacer tratamientos endoscópicos.

\section{REFERENCIAS}

1. Garris EM, Jolles PR, Cole TJ. Large Urethral Diverticulum presenting as a scrotal tracer collection on renal scintigraphy. Clin Nucl Med. 1996;21(8):661-662.

2. Barbagli G, Selli C, di Cello V, Mottola A. A one-stage urethroplasty for uretral diverticula repair in male paraplegics. $\mathrm{Br} \mathrm{J}$ Urol. 1996;78(6):929-932.

3. De Filippo RE, Kurzrock EA, Stein JP, Skinner DG. A giant urethral diverticulum presenting as a scrotal mass in an adult male. BJU Int. 1999;83(4):522-523.

4. Laungani RG, Angermeier KW, Montague DK. Giant urethral diverticulum in an adult male: A complication of the artificial urinary sphincter. J Urol. 2003;170(4 Pt 1):1307-1308.

5. Jang TL, Blunt LW, Yap RL, Brannigan RE, Gonzalez CM. Large urethral diverticulum presenting as a scrotal mass: urethral reconstruction with ventral onlay buccal mucosa. J Urol. 2004; 171(1):351-352.

6. Paulhac P, Fourcade L, Lesaux N, Alain JL, Colombeau P. Anterior urethral valves and diverticula. BJU Int. 2003;92(5): 506-509.

Correspondencia autor: Dr. J.A Gómez Pascual

Servicio de Urología Hospital Civil.

Complejo Hospitalario Carlos Haya

Plaza Hospital Civil s/n - 29009 Málaga

E-mail autor: joseangelgomezpascual@hotmail.com

Información artículo: Nota Clínica

Trabajo recibido: febrero 2007

Trabajo aceptado: marzo 2007 